\title{
Transforaminal endoscopic discectomy versus conventional microdiscectomy for lumbar discherniation: a systematic review and meta-analysis
}

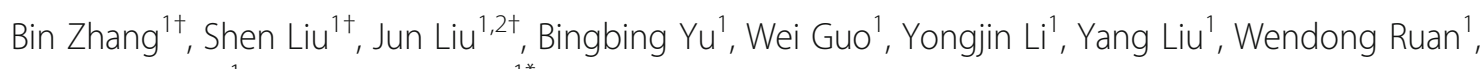
Guangzhi Ning ${ }^{1}$ and Shiqing Feng ${ }^{1 *}$

\begin{abstract}
Background: The open microdiscectomy is the most common surgical procedure for the decompression of radiculopathy caused by lumbar disk herniation. To date, a variety of minimally invasive (MI) techniques have been developed. In the last decades, endoscopic techniques have been developed to perform discectomy. The transforaminal endoscopic discectomy (TED) with posterolateral access evolved out of the development of endoscopic techniques.

Methods: A systematic literature search was performed using the PubMed, EMBASE, and Cochrane Library databases for trials written in English. The randomized trials and observational studies that met our inclusion criteria were subsequently included. Two reviewers respectively extracted data and estimated the risk of bias. All statistical analyses were performed using Review Manager 5.3.

Results: Five prospective and four retrospective studies involving 1527 patients were included. The results of the meta-analysis indicated that there were significant differences between the two groups in length of hospital stay $(\mathrm{MD}=-8.41,95 \% \mathrm{Cl}-10.26,-6.56 ; p$ value $<0.00001)$. However, there were no significant differences in the leg visual analog scale (VAS) scores, the Oswestry Disability Index (ODI) scores, and the incidence of complications and recurrence.
\end{abstract}

Conclusions: The transforaminal endoscopic discectomy is superior to open microdiscectomy in the length of hospital stay. However, there were no differences in leg pain, functional recovery, and incidence of complications between TED and MD in treating $L D H$.

Keywords: Transforaminal endoscopic discectomy, Conventional microdiscectomy, Meta-analysis

\section{Background}

Lumbar disk herniation (LDH) is a common medical condition with a pathological process that leads to spinal surgery. The fibrous ring of an intervertebral disk is fractured and allows the soft central portion, the nucleus pulposus, to bulge out beyond the damaged fibrous rings. LDH is considered to be

\footnotetext{
* Correspondence: sqfeng@tmu.edu.cn

${ }^{+}$Bin Zhang, Shen Liu and Jun Liu contributed equally to this work.

'Department of Orthopedics, Tianjin Medical University General Hospital, No. 154 Anshan Road, Heping District, Tianjin 300052, People's Republic of China Full list of author information is available at the end of the article
}

the most prevalent spinal disk herniation and always causes a series of signs and symptoms. One of the most challenging medical problems is sciatica symptoms. Sciatica affects millions of individuals worldwide [1]. The nerve root compression caused by the bulge of the nucleus pulposus and the secondary inflammatory reaction represent two crucial factors that result in lumbosacral radicular syndrome [2]. With the aggravation of $\mathrm{LDH}$, incontinence may develop [3].

Currently, early conservative treatment is used when the symptoms are not serious. However, surgery is adopted 
when conservative treatment fails, or complaints worsen over time [4, 5]. In 1934, lumbar disk herniation was the first condition treated surgically by performing an open laminectomy and discectomy [6]. With the introduction of the microscope, the open lumbar discectomy was refined into open microdiscectomy (MD) [7]. Currently, the open microdiscectomy is the most common surgical procedure for decompression of radiculopathy caused by lumbar disk herniation [8]. Since then, a variety of minimally invasive (MI) techniques have been developed. The minimally invasive techniques provide a similar view with a small incision and better cosmetic results $[9,10]$. In the last decades, endoscopic techniques have been developed to perform discectomy under direct view and local anesthesia. The transforaminal endoscopic discectomy (TED) with posterolateral access evolved out of the development of endoscopic techniques [11-15]. The lateral access of transforaminal endoscopic discectomy to the spinal canal under continuous visualization has been developed since the late 1990s [16].

The indications for transforaminal endoscopic treatment are similar to classical open microdiscectomy procedures $[17,18]$. However, a controversy remains over whether TED or MD should be utilized in clinical practice. It is therefore necessary to compare the clinical efficacies of different procedures to generate data that can be used to formulate clinical guidelines. Our goal was to systematically review, grade, and perform a meta-analysis of existing comparative studies. In this review, we compared the safety and efficacy of TED and MD for treating LDH patients.

\section{Methods}

\section{Study design}

The standards set by the Preferred Reporting Items for Systematic Reviews and Meta-Analyses (PRISMA) guidelines were used to construct this systematic review. The 27-item checklist and 4-phase flow diagram of PRISMA were both consulted.

\section{Literature search}

The PubMed, EMBASE, and Cochrane Library databases were searched up to January 2017 to identify studies comparing transforaminal endoscopic discectomy with microdiscectomy for the treatment of lumbar disk herniation. The search terms included "transforaminal endoscopic discectomy," "microdiscectomy," "endoscopic," "minimally invasive," and "lumbar disk herniation."

References from each article directly comparing the two kinds of surgeries, in addition to review articles discussing the safety and efficacy of the two procedures, were cross-referenced to identify additional relevant studies.

\section{Inclusion and exclusion criteria}

For inclusion in the systematic review, the articles were required to meet the following eligibility criteria: (1) patients suffering from lumbar disk herniation; (2) papers reporting the results of clinical studies evaluating transforaminal endoscopic discectomy and microdiscectomy; (3) patients followed for a minimum of 2 weeks; and (4) papers published in English prior to January 2017. Randomized controlled trials (RCTs) were identified as the primary studies for analysis. For inclusion in statistical analysis, the patients in a particular study must have been randomized to either TED or MD groups. Studies were excluded from the analysis if they included patients who had an infection, traumatic fracture, previous spinal surgery at the same disk level, and spinal stenosis among other conditions. The inclusion criteria for each study are listed in Table 1.

Table 1 Summary of study criteria-prospective studies and retrospective studies

\begin{tabular}{|c|c|c|c|c|c|c|}
\hline Study & $\begin{array}{l}\text { Study } \\
\text { type }\end{array}$ & $\begin{array}{l}\text { Sample } \\
\text { size }\end{array}$ & Av. age & $\begin{array}{l}\text { Mean duration of } \\
\text { follow-up (months) }\end{array}$ & Gender (M/F) & Level \\
\hline Hermantin et al. [20] & $\mathrm{RCT}$ & 60 & 39 vs. 40 & $31(19-42)$ vs. $32(21-42)$ & 22:8/17:13 & L2-L3L3-L4L4-L5L5-S1 \\
\hline $\begin{array}{l}\text { Mayer and Brock } \\
\text { [21] }\end{array}$ & $\mathrm{RCT}$ & 40 & $39.8 \pm 10.4$ vs. $42.7 \pm 10$ & 6.9 & $12: 8 / 14: 6$ & L2-L3L3-L4L4-L5 \\
\hline Ruetten et al. [10] & $\mathrm{RCT}$ & 129 & 43 & 24 & - & $\begin{array}{l}\text { L1-L2L2-L3L3-L4L4-L5L5- } \\
\text { S1 }\end{array}$ \\
\hline Gibson et al. [22] & $\mathrm{RCT}$ & 140 & $42.0 \pm 9$ vs. $39 \pm 9$ & 24 & $30: 40 / 40: 30$ & L3-L4L4-L5L5-S1 \\
\hline Akçakaya et al. [27] & $\mathrm{RCT}$ & 30 & 44.1 & - & - & - \\
\hline Kim et al. [23] & Retro & 902 & 34.9 vs. 44.4 & 23.6 & $\begin{array}{l}\text { 188:107/ } \\
392: 215\end{array}$ & $\begin{array}{l}\text { L1-L2L2-L3L3-L4L4-L5L5- } \\
\text { S1 }\end{array}$ \\
\hline Lee et al. [24] & Retro & 60 & 39.3 vs. 39.6 & $38.2(32-45)$ vs. $36.8(35-42)$ & $22: 8 / 22: 8$ & L4-L5L5-S1 \\
\hline Ahn et al. [25] & Retro & 66 & $\begin{array}{l}22.41 \pm 1.68 \text { vs. } 22.18 \pm \\
1.51\end{array}$ & $\begin{array}{l}13.69+1.26 \text { vs. } 13.41+ \\
1.02\end{array}$ & $32: 0 / 34: 0$ & L4-L5 \\
\hline Hsu et al. [26] & Retro & 100 & - & 20.4 & - & L1-L2L2-L3L3-L4L4-L5 \\
\hline
\end{tabular}




\section{Risk of bias}

The risk of bias of the Cochrane Handbook for Systematic Reviews of Interventions was evaluated by using the risk of bias tool implemented in Review Manager 5.3. The included RCTs were evaluated for the risk of bias, which included assessments of adequate sequence generation, allocation of concealment, blinding, incomplete outcome data, and freedom from other biases. The judgment of each entry involved assessing the risk of bias as "low risk," "high risk," or "unclear risk," indicating either a lack of information or uncertainty over the potential for bias. Two reviewers independently assessed each RCT, and any disagreements were resolved by discussion and consensus.

\section{Data extraction}

Two authors independently extracted the following data. Any disagreements were resolved via discussion among the three reviewers. The data extracted from the studies included the following: study characteristics, types of interventions, follow-up duration, and outcome parameters.

\section{Outcome measures}

The "degree of pain relief" (visual or verbal analog pain scale (VAS) score) and the functional improvement (Oswestry Disability Index (ODI)) were the primary outcome measures of the effectiveness of the surgeries. The secondary outcome measures were average duration of surgery, complications, hospital stay, recurrence, and satisfactory outcome.

\section{Statistical analysis}

The data were collected and analyzed using Review Manager 5.3. Differences in pain, functional improvement, average duration of surgery, and hospital stay between the TED and MD groups were analyzed using the independent samples $t$ test under a random-effects model. Risk ratios (RRs) and 95\% confidence intervals (CIs) were used to evaluate the dichotomous outcomes, such as the incidence of complications. The differences are displayed using a forest plot. The $I^{2}$ statistic [19] (ranging from 0 to $100 \%$ ) was applied to quantify between-study heterogeneity that was not attributed to chance $\left(I^{2}=0-25 \%\right.$, no heterogeneity; $I^{2}=25-50 \%$, moderate heterogeneity; $I^{2}=50-75 \%$, large heterogeneity; and $I^{2}=75-100 \%$, extreme heterogeneity). A $p$ value < 0.05 was considered statistically significant.

\section{Results}

\section{Literature search}

A total of 2397 records were identified through the PubMed, EMBASE, and the Cochrane Library database. Following the exclusion of 369 duplicate items, 2381 articles were screened for review, and 42 that met the inclusion criteria were selected. A total of 33 full-text articles were excluded due to either the absence of a comparison between transforaminal endoscopic discectomy and conventional microdiscectomy or the absence of an appropriate statistical analysis. Nine studies $[10,20-27]$ were ultimately included in the meta-analysis (Fig. 1).

\section{Risk of bias in included studies}

We used the risk of bias tool implemented in Review Manager 5.3 to evaluate the risk of bias of the Cochrane Handbook for Systematic Reviews of Interventions. The particular information of the risk of bias of the included articles is demonstrated in Fig. 2. Four $[10,20-22]$ of five studies comprehensively

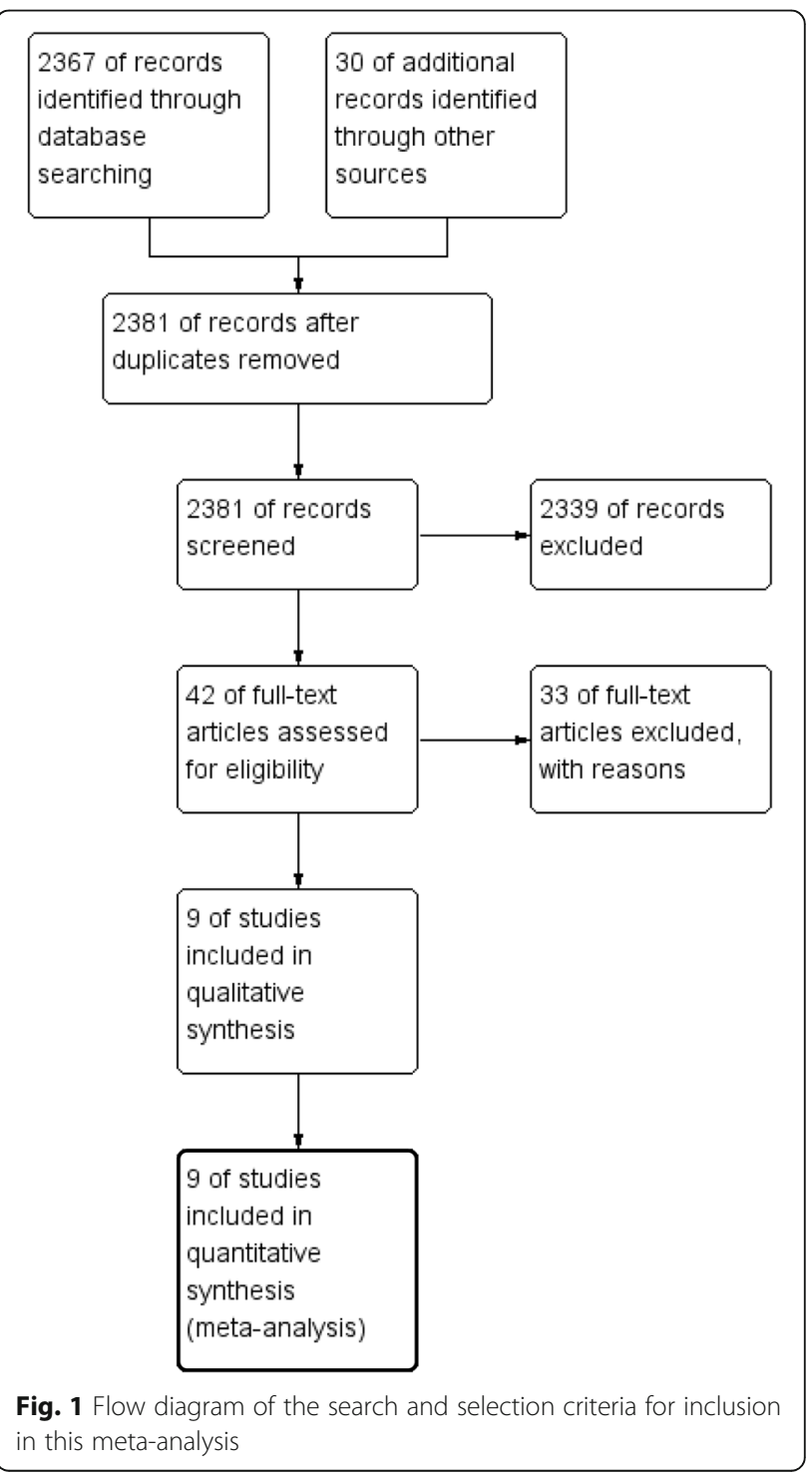


described the generation of a randomized sequence. The patients were not blinded to the treatment allocation in one study [10], which consisted of four indistinct studies [20-22, 27]. One article [27] displayed a high risk of bias for the incomplete outcomes. The rest of the included articles displayed a low risk of bias for the incomplete outcomes, selective outcome reporting, and other biases.

\section{Demographics of the studies included in the review}

Five $[10,20-22,27]$ of the nine studies were prospective studies, and four [24-26, 28, 29] were retrospective studies. These studies included 1527 patients, 399 of whom were included in the prospective studies, and 1128 of whom were included in the retrospective studies. Statistical analysis was performed in the five prospective studies and four retrospective studies. Differences in age, gender, and level were noted; however, these differences were not statistically significant. Follow-up periods ranged from 6.9 to 24 months in duration (Table 1).

\section{Outcome analyses: leg pain}

VAS scores were available in two of the RCT studies. Mayer and Brock [21] show that the VAS scores were $8.23 \pm 1.3$ and $7.67 \pm 1.9$ in the TED and MD groups at 2 years postoperation, respectively. Both groups showed a significant difference between preoperative and postoperative scores. Gibson et al. [22] showed that the VAS scores were $1.9 \pm 2.6$ and $3.5 \pm 3.1$ in the TED and MD groups at 2 years postoperation, respectively. Meta-analyses were performed in these two studies. Although the heterogeneity was high ( $I^{2}$ up to $89 \%$ ), slightly better leg pain relief was observed in the TED group at 2 years and no differences were noted after 2 years of follow-up (Fig. 3a).

Two retrospective studies $[25,26]$ reported VAS scores (Fig. 3b). Meta-analyses were also performed in these two studies. Although the $I^{2}$ was low, the credibility was not high. Similar outcomes were reported in these two retrospective studies compared to the RCT studies. No significant differences were observed between the TED and MD groups (SMD $=-0.13,95 \%$ CI $-0.58,0.33 ; p=0.58$ ).

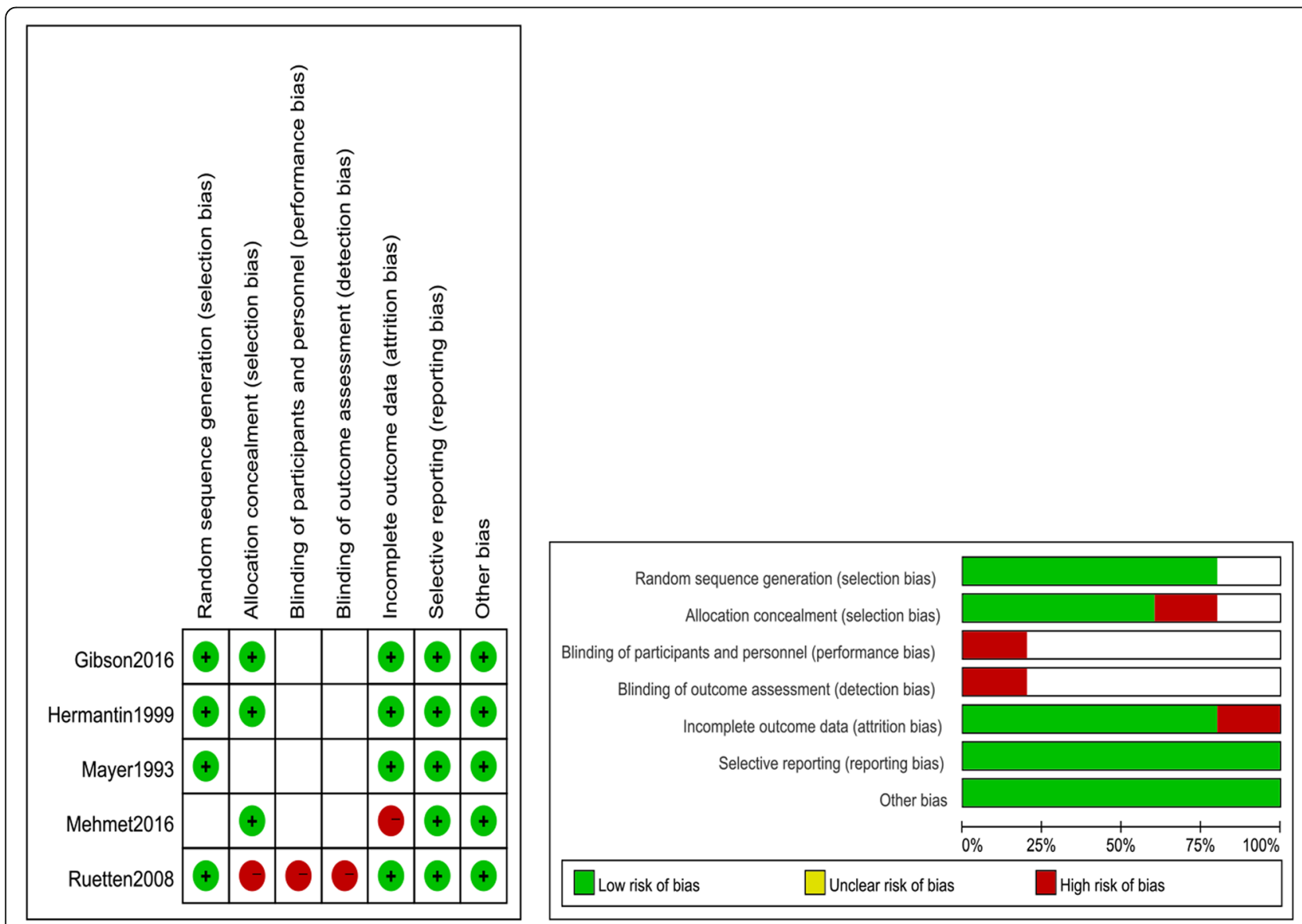

Fig. 2 Risk of bias assessment of each included study. a Risk of bias graph. b Risk of bias summary 


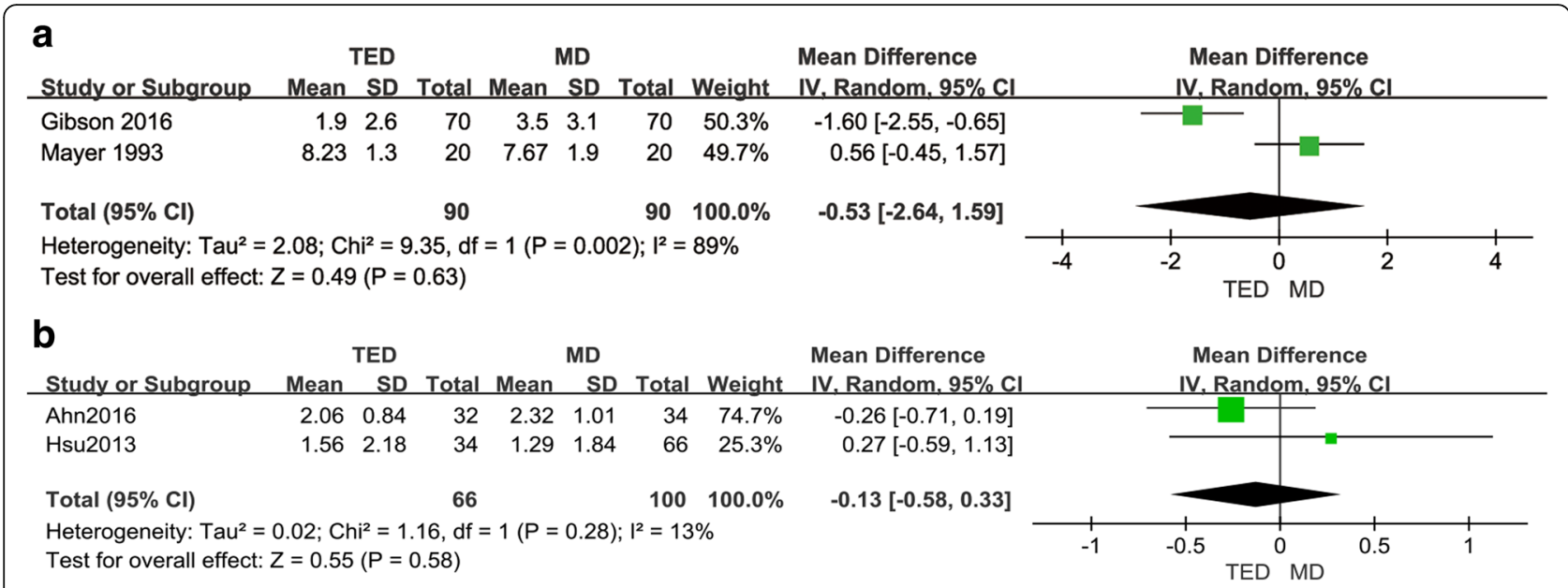

Fig. 3 A comparison of MD vs. TED with respect to pain level following surgery in RCTs (a) and retrospective studies (b)

\section{Outcome analyses: functional recovery}

Function was measured using an ODI. Only two retrospective studies $[25,26,28]$ had reported the ODI scores. Ahn et al. [25] reported that the ODI scores were $9.63 \pm 2.31$ and $10.68 \pm 2.67$ in the TED and MD groups, respectively. Hsu et al. [26] reported that the ODI was $6.42 \pm 9.82$ and $3.29 \pm 6.94$ in the TED and MD groups, respectively. There were no significant differences between the TED and MD groups (Fig. 4).

\section{Operative time}

The average duration of surgery was available in two of the RCT studies. Mayer and Brock [21] showed that the operative time was $40.7 \pm 11.3$ and $58.2 \pm 15.2 \mathrm{~min}$ in the TED and MD groups, respectively. Gibson et al. [22] showed that the VAS scores were $28 \pm 11$ and $29 \pm$ $12 \mathrm{~min}$ in the TED and MD groups, respectively. Meta-analyses were performed in these two studies. Although a shorter operative time was observed in the TED group, there were no significant differences between the two groups (Fig. 5).

\section{Stay in hospital}

Only two retrospective studies [24, 25] reported hospital stay (Fig. 6). Meta-analyses were performed in these two studies. Both studies reported a shorter hospital stay in the TED group vs. the MD group. The time was $19.5 \pm$ 30.12 vs. $71.96 \pm 60.05$ and $7.5 \pm 2.63$ vs. $15.65 \pm 4.8 \mathrm{~h}$, respectively. The differences between the TED and MD groups was statistically significant $(\mathrm{MD}=-8.41,95 \% \mathrm{CI}$ - 10.26, - 6.56; $p<0.00001$ ).

\section{Complications}

Both the RCT and retrospective studies recorded the postoperative complications (Fig. 7a). The conditions related to the complications were available in three of the RCT studies [10, 20, 22]. There were no complications reported in the articles of Hermantin et al. [20] and Gibson et al. [22]. No complications were reported in the TED group, but four complications and three complications were reported in the MD group [10, 22]. No significant differences were reported between the TED and MD groups ( $\mathrm{RR}=0.23,95 \% \mathrm{CI} 0.01,4.13 ; p=0.32$ ).

Three retrospective studies $[23,25,26]$ reported complications (Fig. 7b). Meta-analyses were also performed in these three studies. Similar outcomes were reported in these three retrospective studies compared to the RCT studies. However, the rate of complications was slightly higher in the MD group; differences between the TED and MD groups were not statistically significant.

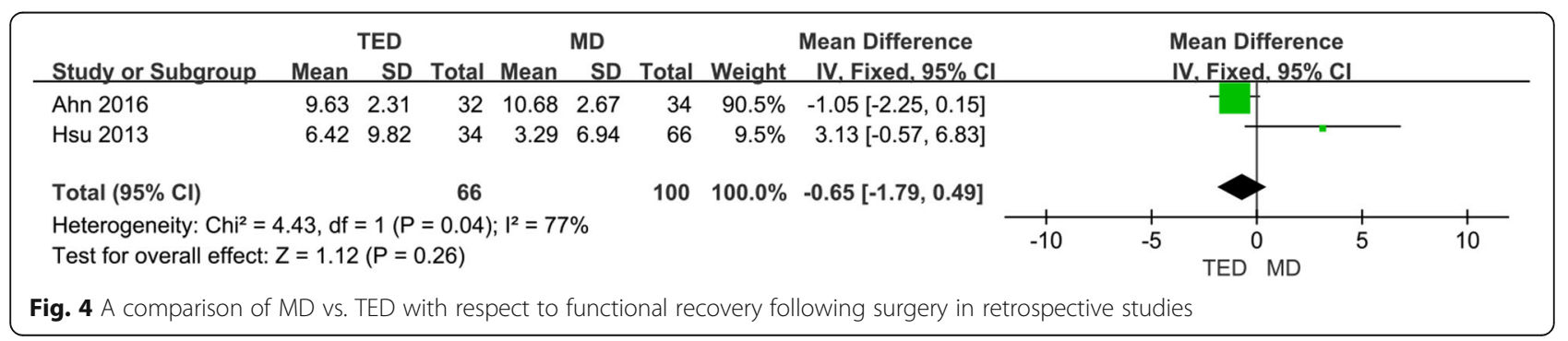




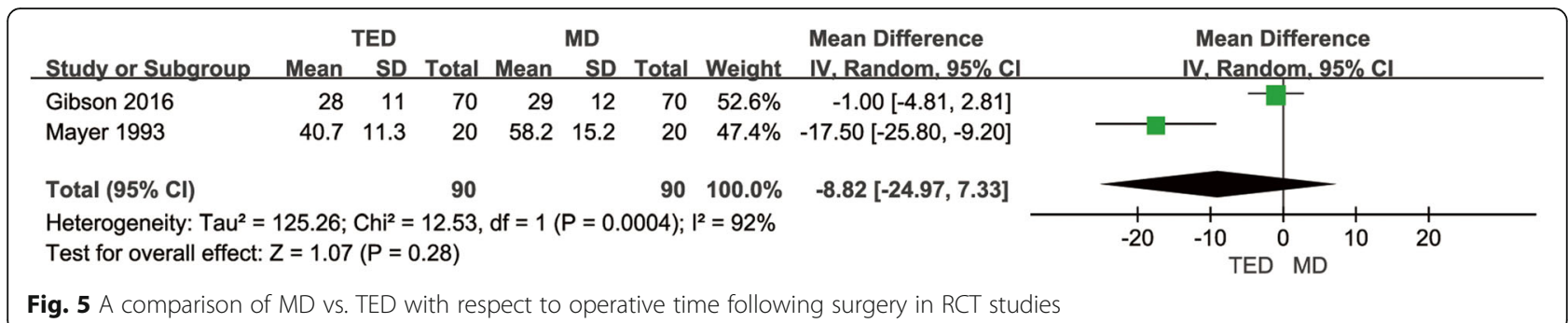

\section{Rate of recurrence}

The recurrence was recorded in three of the RCT studies $[10,21,22]$. All the RCT studies reported a higher rate of recurrence in the TED group. No significant differences were observed between the TED and MD groups $(\mathrm{RR}=1.77,95 \%$ CI 0.66, 4.8; $p=0.26$ ) (Fig. 8a).

Four retrospective studies [23-26] reported recurrence. Similar outcomes were observed in these four retrospective studies compared to the RCT studies. A higher rate of recurrence was observed in the TED group, and the difference between the TED and MD groups was statistically significant $(\mathrm{RR}=1.65,95 \% \mathrm{CI}$ $1.08,2.53 ; p=0.02$ ) (Fig. 8b).

\section{Discussion}

Lumbar open microdiscectomy is a popular procedure for the surgical treatment of lumbar disk herniation [28]. However, the open microdiscectomy surgery often requires a large incision to provide optimal vision. During the surgery, the paravertebral muscles are retracted, and the spinal lamina and facet joint are removed. This surgery can cause scarring and instability of the spine, which causes clinical symptoms in $10 \%$ or more of patients [29]. The transforaminal endoscopic discectomy was developed in the 1990s. Compared to the open microdiscectomy, it has several advantages. The TED can be performed under local anesthesia; thus, the rate of anesthesia-associated complications is low. The risk of scar formation and instability of the spine is also decreased [30-33]. A review [34] of the comparisons between TED and MD showed that TED was strongly favored. It is therefore necessary to compare the clinical efficacies of the different procedures to generate data that help surgeons make clinical decisions and develop optimal treatments.
We summarized the results of studies comparing transforaminal endoscopic discectomy and open microdiscectomy and performed a meta-analysis to compare the effectiveness and safety of these two surgeries for treating lumbar disk herniation. We analyzed the effectiveness of these two procedures by evaluating improvements in patients' pain, functional scores, average duration of surgery, and hospital stay. We also analyzed the safety of these two procedures by evaluating complications and recurrence of LDH. We included five prospective studies and four retrospective studies involving 1527 patients in our analysis (Table 2).

No significant difference in both leg pain and function recovery was observed between TED and MD. Both RCTs and retrospective studies support the evidence that the transmuscular approach to the transforaminal endoscopic discectomy is as effective as the conventional open microdiscectomy requiring paravertebral muscle retraction. It can be explained that the clinical symptoms were caused by the decompression of the nerve root due to the herniated disk [35]. Both surgical procedures can remove nerve compression. However, several studies [36] suggested that clinical outcomes were associated with paravertebral muscle injury. Additionally, some factors such as different sampling dates, different peri- and intraoperative procedures, and different surgeons may have influenced the clinical outcomes.

The results in operative times and length of hospital stay were difficult to interpret. Although the operative times of the TED group was slightly shorter than the MD group, no significant difference was observed between TED and MD groups. The differences in how operative time was defined are important. Whether the anesthesia time was considered into the operative time,

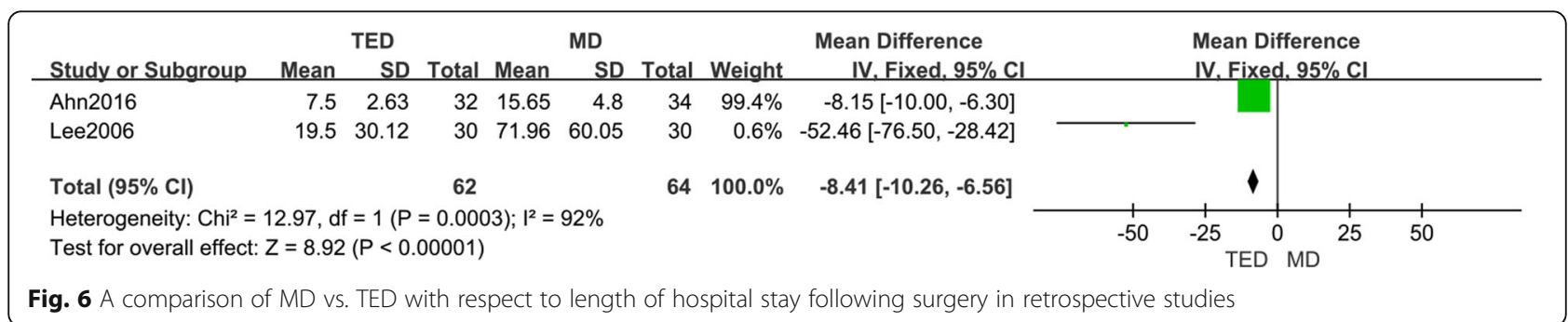




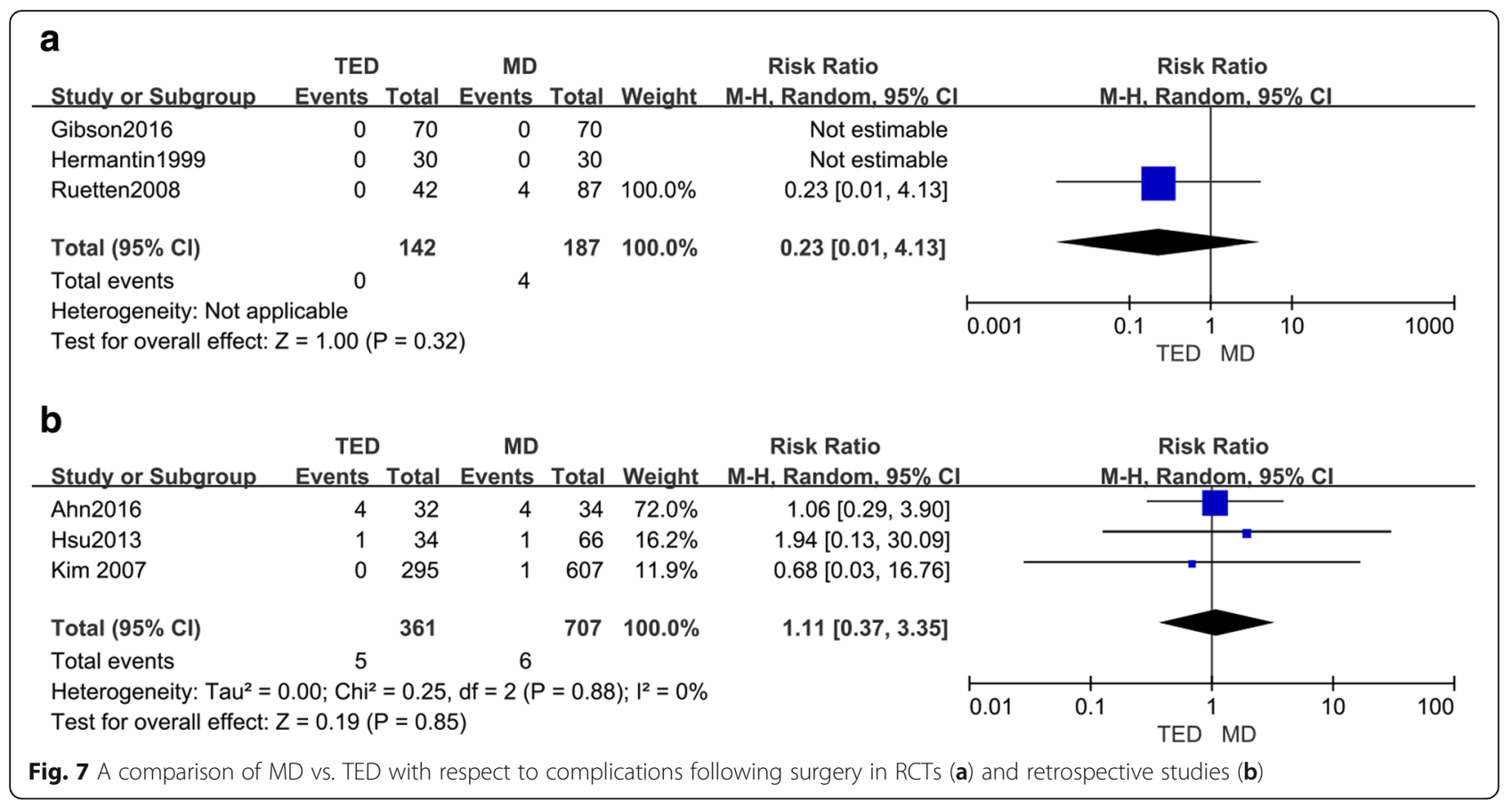

it had a large influence on operative time. Moreover, the variability in the techniques used was also a factor [37]. The length of hospital stay was much shorter in the TED group compared to that in the MD group. Transforaminal endoscopic discectomy may be associated with less muscle damage, among other outcomes [38], which allows the early recovery of patients. Additionally, economic factors should be considered.
In this meta-analysis, no significant difference in rates of total complications was observed between the two groups. Some studies $[25,26]$ suggested that the TED approach would be associated with a higher rate of complications. A limited surgical exposure leads to difficulty in surgery, and therefore, it is easier to cause nerve damage and other complications [39]. However, other research suggests the opposite because the small incision

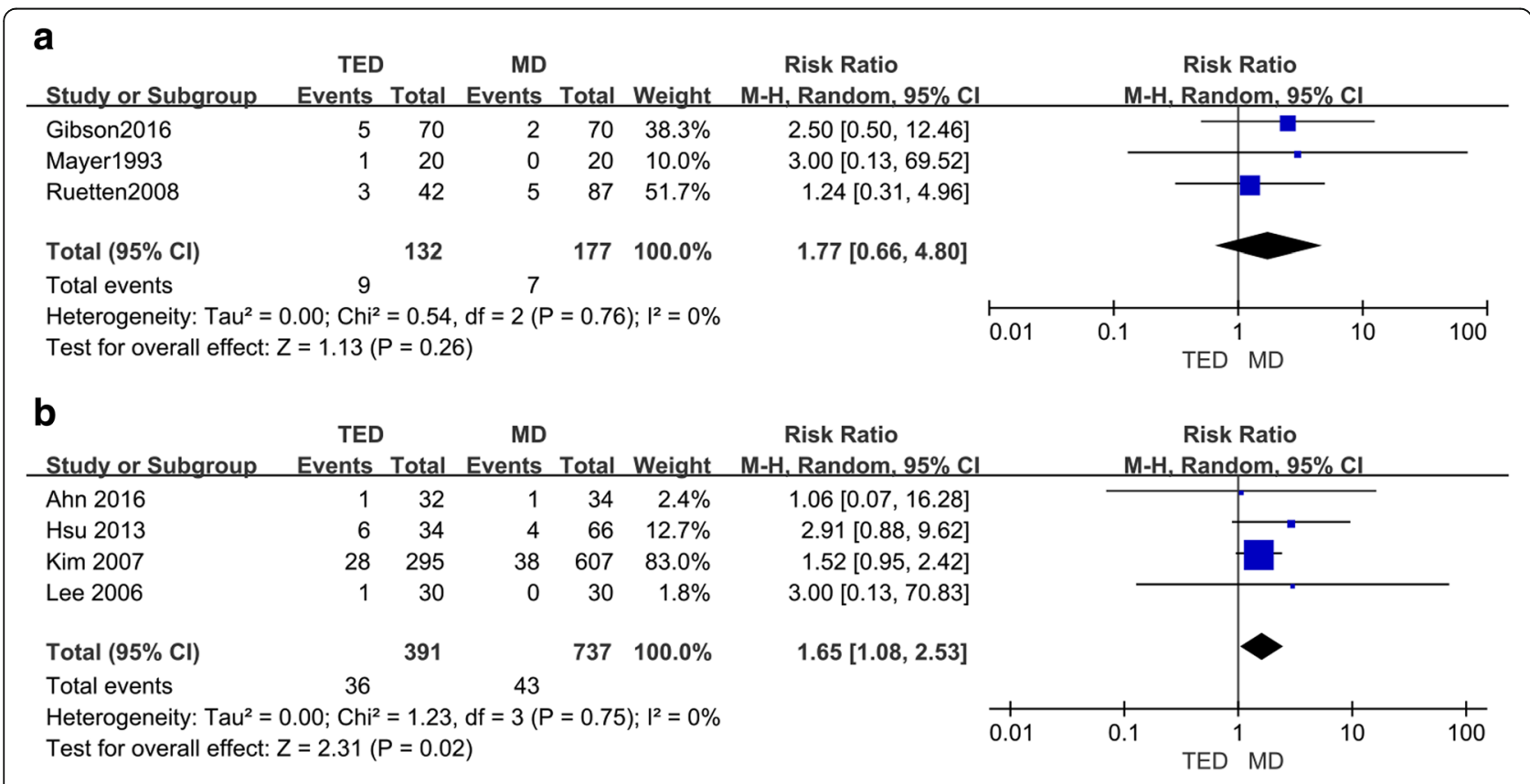

Fig. 8 A comparison of MD vs. TED with respect to the rate of recurrence following surgery in RCTs (a) and retrospective studies (b) 
Table 2 Summary of information of the prospective studies and retrospective studies

\begin{tabular}{|c|c|c|c|c|c|c|c|}
\hline Study & Low-back pain & Leg pain & ODI & Recurrence & Hospital stay & Complications & $\begin{array}{l}\text { Average duration } \\
\text { of surgery (min) }\end{array}$ \\
\hline $\begin{array}{l}\text { Hermantin et } \\
\text { al. [20] }\end{array}$ & - & 1.2 vs. 1.9 & - & - & - & 0 vs. 0 & - \\
\hline $\begin{array}{l}\text { Mayer and } \\
\text { Brock [21] }\end{array}$ & $10 / 19$ vs. $15 / 20$ & $\begin{array}{l}8.23 \pm 1.3 \text { vs. } 7.67 \\
\pm 1.9\end{array}$ & - & $\begin{array}{l}1 / 20 \text { vs. } 0 / \\
20\end{array}$ & - & - & $\begin{array}{l}40.7 \pm 11.3 \text { vs. } 58.2 \\
\pm 15.2\end{array}$ \\
\hline $\begin{array}{l}\text { Ruetten et al. } \\
\text { [10] }\end{array}$ & - & - & - & 3 vs. 5 & - & 0 vs. 4 & - \\
\hline $\begin{array}{l}\text { Gibson et al. } \\
\text { [22] }\end{array}$ & $\begin{array}{l}2.50 \pm 2.5 \text { vs. } 3.0 \\
\pm 2.8\end{array}$ & $\begin{array}{l}1.9 \pm 2.6 \text { vs. } 3.5 \pm \\
3.1\end{array}$ & $18 \pm 17$ vs. $22 \pm 20$ & 5 vs. 2 & $\begin{array}{l}0.7 \pm 0.7 \text { vs. } 1.4 \pm \\
1.3 \text { days }\end{array}$ & 0 vs. 0 & $28 \pm 11$ vs. $29 \pm 12$ \\
\hline Mehmet [27] & - & - & - & - & 1.13 vs. 1.2 days & - & 94 vs. 71 \\
\hline Kim et al. [23] & - & - & - & $\begin{array}{l}28 / 295 \text { vs. } \\
38 / 607\end{array}$ & - & 0 vs. 1 & - \\
\hline Lee et al. [24] & - & - & - & 1 vs. 0 & $\begin{array}{l}19.5 \pm 30.12 \text { vs. } 71.9 \\
\pm 60.05 \mathrm{~h}\end{array}$ & - & $\begin{array}{l}42.6 \pm 14.21 \text { vs. } \\
65.1 \pm 23.17\end{array}$ \\
\hline Ahn et al. [25] & $\begin{array}{l}2.50 \pm 0.62 \text { vs. } \\
2.91 \pm 0.67\end{array}$ & $\begin{array}{l}2.06 \pm 0.84 \text { vs. } \\
2.32 \pm 1.01\end{array}$ & $\begin{array}{l}9.63 \pm 2.31 \text { vs. } \\
10.68 \pm 2.67\end{array}$ & 1 vs. 1 & $\begin{array}{l}7.50 \pm 2.63 \text { vs. } 15.65 \\
\pm 4.80 \mathrm{~h}\end{array}$ & 4 vs. 4 & $\begin{array}{l}48.66 \pm 6.45 \text { vs. } \\
53.71 \pm 8.49\end{array}$ \\
\hline Hsu et al. [26] & & $\begin{array}{l}1.56 \pm 2.18 \text { vs. } \\
1.29 \pm 1.84\end{array}$ & $\begin{array}{l}6.42 \pm 9.82 \text { vs. } \\
3.29 \pm 6.94\end{array}$ & 6 vs. 4 & & 1 vs. 1 & $\begin{array}{l}86.5 \pm 45.9 \text { vs. } 48.1 \\
\pm 9.2\end{array}$ \\
\hline
\end{tabular}

and minimal internal tissue damage make it possible for a shorter recovery period and minimization of scar tissue $[40,41]$. No significant difference in rates of recurrence was observed between the two groups.

One limitation of this study was the small number of RCTs. Although five RCTs were included in this article, different outcomes could only be extracted from a few studies. It made assessing the effectiveness and safety of the interventions on the different surgical approaches difficult. Another limitation of this review was that clinical heterogeneity, which cannot be resolved completely, may be associated with inconsistency of outcomes.

\section{Conclusions}

Our study demonstrated that transforaminal endoscopic discectomy was superior to open microdiscectomy in the length of hospital stay. However, there was no difference in leg pain, functional recovery, and incidence of complications between TED and MD in treating LDH. Prior to selecting a surgical procedure for the management of $\mathrm{LDH}$, the benefits and risks of the procedure discussed herein must be taken into consideration. Additional studies must be performed to guide the clinical decision-making process.

\section{Abbreviations \\ LDH: Lumbar disk herniation; MD: Microdiscectomy; MI: Minimally invasive; PRISMA: Preferred Reporting Items for Systematic Reviews and Meta-Analyses; SMD: Standardized mean differences; TED: Transforaminal endoscopic discectomy}

\section{Acknowledgements}

The authors are grateful to the participants and researchers of the primary studies identified for the present review. They would like to thank the editorial board of Journal of Orthopaedic Surgery and Research for the review and critique, which aided in improving the manuscript. The authors alone are responsible for the views expressed, which are not necessarily reflected by any institution.

\section{Funding}

This work was supported by the National Natural Science Foundation of China (81501899); the State Key Program of the National Natural Science Foundation of China (81330042); the Special Program for Sino-Russian Joint Research Sponsored by the Ministry of Science and Technology, China (2014DFR31210); the Key Program Sponsored by the Tianjin Science and Technology Committee, China (13RCGFSY19000, 14ZCZDSY00044); the Science Foundation of Tianjin Medical University for Young Scholar (2014KYQ01); and the Science Foundation of Tianjin Medical University General Hospital for Young Scholar (ZYYFY2014037).

Availability of data and materials

All data and materials were in full compliance with the journal's policy.

Authors' contributions

BZ and SL conceived the study design. JL and BBY performed the study, collected the data, and contributed to the study design. BZ and LJ prepared the manuscript. SQF and SL edited the manuscript. All authors read and approved the final manuscript.

Ethics approval and consent to participate

Ethical approval of this study was not necessary, as systematic review and meta-analyses do not involve patients.

\section{Consent for publication}

Not applicable.

\section{Competing interests}

The authors declare that they have no competing interests.

\section{Publisher's Note}

Springer Nature remains neutral with regard to jurisdictional claims in published maps and institutional affiliations.

\section{Author details}

${ }^{1}$ Department of Orthopedics, Tianjin Medical University General Hospital, No. 154 Anshan Road, Heping District, Tianjin 300052, People's Republic of China. ${ }^{2}$ Department of Orthopedics, First Affiliated Hospital of Gannan Medical University General Hospital, No. 23 Qingnian Road, Zhanggong District, Ganzhou 341000, People's Republic of China. 


\section{Received: 23 September 2017 Accepted: 15 June 2018}

\section{Published online: 05 July 2018}

\section{References}

1. Konstantinou K, Dunn KM. Sciatica: review of epidemiological studies and prevalence estimates. Spine. 2008;33:2464-72.

2. Boonstra AM, Preuper HRS, Reneman MF, Posthumus JB, Stewart RE. Reliability and validity of the visual analogue scale for disability in patients with chronic musculoskeletal pain. Int J Rehabil Res. 2008;31:165-9.

3. Ma D, Liang Y, Wang D, Liu Z, Zhang W, Ma T, et al. Trend of the incidence of lumbar disc herniation: decreasing with aging in the elderly. Clin Interv Aging. 2013:8:1047-50.

4. Lequin MB, Verbaan $D$, Jacobs WC, Brand $R$, Bouma GJ, Vandertop WP, et al. Surgery versus prolonged conservative treatment for sciatica: 5-year results of a randomised controlled trial. BMJ Open. 2013;3:13-7.

5. Awad JN, Moskovich R. Lumbar disc herniations: surgical versus nonsurgical treatment. Clin Orthop Relat Res. 2006:443:183-97.

6. Mixter W, Barr J. Rupture of the intervertebral disc with involvement of the spinal canal. N Engl J Med. 1934;211:210-5.

7. Caspar W. A new surgical procedure for lumbar disc herniation causing less tissue damage through a microsurgical approach. In: Wüllenweber R, Brock M, Hamer J, Klinger M, Spoerri O, editors. Lumbar disc adult hydrocephalus. Berlin, Heidelberg: Springer; 1977. p. 74-80.

8. Koebbe CJ, Maroon JC, Abla A, El-Kadi H, Bost J. Lumbar microdiscectomy: a historical perspective and current technical considerations. Neurosurg Focus. 2002:13:E3.

9. Ruetten S, Komp M, Merk H, Godolias G. Use of newly developed instruments and endoscopes: full-endoscopic resection of lumbar disc herniations via the interlaminar and lateral transforaminal approach. J Neurosurg Spine. 2007;6:521-30.

10. Ruetten S, Komp M, Merk H, Godolias G. Full-endoscopic interlaminar and transforaminal lumbar discectomy versus conventional microsurgical technique: a prospective, randomized, controlled study. Spine. 2008;33:931-9.

11. Deen HG. Posterolateral endoscopic excision for lumbar disc herniation: surgical technique, outcome, and complications in 307 consecutive cases. Spine. 2002;27:2081-2.

12. Tsou PM, Yeung AT. Transforaminal endoscopic decompression for radiculopathy secondary to intracanal noncontained lumbar disc herniations: outcome and technique. Spine J. 2002;2:41-8.

13. Mathews HH. Transforaminal endoscopic microdiscectomy. Neurosurg Clin N Am. 1996;7:59-63.

14. Lew SM, Mehalic TF, Fagone KL. Transforaminal percutaneous endoscopic discectomy in the treatment of far-lateral and foraminal lumbar disc herniations. J Neurosurg. 2001;94:216-20.

15. Kambin P, Casey K, O'Brien E, Zhou L. Transforaminal arthroscopic decompression of lateral recess stenosis. J Neurosurg. 1996:84:462-7.

16. Ruetten S, Komp M, Godolias G. An extreme lateral access for the surgery of lumbar disc herniations inside the spinal canal using the full-endoscopic uniportal transforaminal approach-technique and prospective results of 463 patients. Spine. 2005;30:2570-8

17. Choi G, Lee SH, Bhanot A, Raiturker PP, Chae YS. Percutaneous endoscopic discectomy for extraforaminal lumbar disc herniations: extraforaminal targeted fragmentectomy technique using working channel endoscope. Spine. 2007:32:E93-9.

18. Kambin P, O'Brien E, Zhou L, Schaffer JL. Arthroscopic microdiscectomy and selective fragmentectomy. Clin Orthop Relat Res. 1998;347:150-67.

19. Higgins JP, Thompson SG. Quantifying heterogeneity in a meta-analysis. Stat Med. 2002;21:1539-58.

20. Hermantin FU, Peters T, Quartararo L, Kambin P. A prospective, randomized study comparing the results of open discectomy with those of video-assisted arthroscopic microdiscectomy. J Bone Joint Surg Am. 1999;81:958-65.

21. Mayer HM, Brock M. Percutaneous endoscopic discectomy: surgical technique and preliminary results compared to microsurgical discectomy. J Neurosurg. 1993:78:216-25.

22. Gibson JNA, Subramanian AS, Scott CEH. A randomised controlled trial of transforaminal endoscopic discectomy vs microdiscectomy. Eur Spine J. 2017;26:847-56.

23. Kim MJ, Lee SH, Jung ES, Son BG, Choi ES, Shin JH, et al. Targeted percutaneous transforaminal endoscopic diskectomy in 295 patients: comparison with results of microscopic diskectomy. Surg Neurol. 2007:68:623-31.

24. Lee SH, Chung SE, Ahn Y, Kim TH, Park JY, Shin SW. Comparative radiologic evaluation of percutaneous endoscopic lumbar discectomy and open microdiscectomy: a matched cohort analysis. Mt Sinai J Med. 2006;73:795-801.

25. Ahn SS, Kim SH, Kim DW, Lee BH. Comparison of outcomes of percutaneous endoscopic lumbar discectomy and open lumbar microdiscectomy for young adults: a retrospective matched cohort study. World Neurosurg. 2016;86:250-8.

26. Hsu HT, Chang SJ, Yang SS, Chai CL. Learning curve of full-endoscopic lumbar discectomy. Eur Spine J. 2013;22:727-33.

27. Akcakaya MO, Yorukoglu AG, Aydoseli A, Aras Y, Sabanci PA, Altunrende ME, et al. Serum creatine phosphokinase levels as an indicator of muscle injury following lumbar disc surgery: comparison of fully endoscopic discectomy and microdiscectomy. Clin Neurol Neurosurg. 2016;145:74-8.

28. Schizas C, Tsiridis E, Saksena J. Microendoscopic discectomy compared with standard microsurgical discectomy for treatment of uncontained or large contained disc herniations. Neurosurgery. 2005;57:357-60.

29. Fritsch EW, Heisel J, Rupp S. The failed back surgery syndrome: reasons, intraoperative findings, and long-term results: a report of 182 operative treatments. Spine. 1996:21:626-33.

30. Choi I, Ahn JO, So WS, Lee SJ, Choi IJ, Kim H. Exiting root injury in transforaminal endoscopic discectomy: preoperative image considerations for safety. Eur Spine J. 2013;22:2481-7.

31. Gempt J, Jonek M, Ringel F, Preuss A, Wolf P, Ryang Y. Long-term follow-up of standard microdiscectomy versus minimal access surgery for lumbar disc herniations. Acta Neurochir. 2013;155:2333-8.

32. Peng CW, Yeo W, Tan SB. Percutaneous endoscopic discectomy: clinical results and how it affects the quality of life. J Spinal Disord Tech. 2010:23:425-30.

33. Rahimi-Movaghar V, Rasouli M, Shokraneh F, Moradi-Lakeh M, Vakaro A, Sadeghi-Naini M. Minimally invasive discectomy versus microdiscectomy/discectomy for symptomatic lumbar disc herniation. J Inj Violence Res. 2012:4:61.

34. Gibson JN, Cowie JG, Iprenburg M. Transforaminal endoscopic spinal surgery: the future 'gold standard' for discectomy? A review. Surgeon. 2012;10:290-6.

35. Kamble PC, Sharma A, Singh V, Natraj B, Devani D, Khapane V. Outcome of single level disc prolapse treated with transforaminal steroid versus epidural steroid versus caudal steroids. Eur Spine J. 2016;25:217-21.

36. Kotil K, Tunckale T, Tatar Z, Koldas M, Kural A, Bilge T. Serum creatine phosphokinase activity and histological changes in the multifidus muscle: a prospective randomized controlled comparative study of discectomy with or without retraction. J Neurosurg Spine. 2007;6:121-5.

37. Lee DY, Lee SH. Learning curve for percutaneous endoscopic lumbar discectomy. Neurol Med Chir. 2008;48:383-8.

38. Songer MN, Ghosh L, Spencer DL. Effects of sodium hyaluronate on peridural fibrosis after lumbar laminotomy and discectomy. Spine. 1990:15:550-4

39. Arts MP, Nieborg A, Brand R, Peul WC. Serum creatine phosphokinase as an indicator of muscle injury after various spinal and nonspinal surgical procedures. J Neurosurg Spine. 2007;7:282-6.

40. Knight MT, Ellison DR, Goswami A, Hillier VF. Review of safety in endoscopic laser foraminoplasty for the management of back pain. J Clin Laser Med Surg. 2001;19:147-57.

41. Knight MT, Goswami A, Patko JT, Buxton N. Endoscopic foraminoplasty: a prospective study on 250 consecutive patients with independent evaluation. J Clin Laser Med Surg. 2001;19:73-81. 